\title{
The impact of the XBRL environment on auditing
}

\author{
Yuanqing Mao', Liucheng Zhang, * \\ ${ }^{1}$ School of Accounting, Harbin University of Commerce, Harbin, 150028, China \\ ${ }^{2}$ School of Accounting, Harbin University of Commerce, Harbin, 150028, China \\ zhagnliucheng@126.com
}

Keywords: XBRL, audit, impact

\begin{abstract}
XBRL comes into being with the continuous development of information technology. Its application not only brought a series of positive influence to the audit works, but also made the audit works face the challenge in many aspects. This paper analyzes the effect of XBRL technology on audit and its deficiencies, and proposes corresponding countermeasures to solve problems, so as to hope that XBRL technology can more effectively reduce audit risks and improve audit service quality.
\end{abstract}

\section{The concept of XBRL}

As an extensible business reporting language, XBRL is an emerging electronic financial reporting format. It is mainly caused by the fact that different enterprises have different forms of financial reports. In traditional electronic financial reports, there are problems that need to be converted according to different users, which makes their utilization rate very low. By adding specific labels and classifications to the data in financial accounting, XBRL enables the computer to automatically extract and process the corresponding data according to user requirements. Since XBRL is an xml-based data transfer standard, if the user's browser supports XML, it can browse and download financial reports in XBRL format, just as if the user's browser supports XML.

In the current big data environment, the rapid development of the Internet has made XBRL more important, and also brought profound influence to the audit industry. As a comprehensive economic supervision department, how to make XBRL more meet the audit requirements is a question worth pondering for every auditor.

\section{Positive impact of XBRL on audit}

\subsection{XBRL makes auditing more efficient}

Before using XBRL technology, due to different companies use the financial information system, the background database and information system in May is not compatible with the auditing software, make the auditor needs to be according to different audit software will be the corresponding transformation, financial data and information of the data input is often need to copy and paste by artificial means. After data entry, it is difficult to find relevant data and analyze the data, which is time-consuming and time-consuming. Moreover, many human errors will be generated, which will affect the audit effect and results. After using XBRL technology, as a result of provides the XBRL common technical framework, to ensure that all enterprises of XBRL financial report can be unified data format, enterprises to enter the corresponding transaction data into the computer, the data will form the original data of the enterprise, establish the corresponding database, because of the unity of the data formats, and XBRL financial report system of enterprise financial system can exchange with each other by the uniform interface between data, when need to extract the accounting data, requires only one input can use the same data for many times, don't need to do a second input and lookup, Avoid the possibility of error in the flow. In this way, it not only ensures the authenticity and consistency of the data, but also reduces the workload of relevant 
staff, saves a lot of time for data processing, thus improving the efficiency of auditing.

In addition, XBRL can quickly transform the file format into written words, PDF files, HTML pages, etc., to suit different information users.

\subsection{XBRL broadens the scope of auditing}

Applying XBRL will expand the scope of auditing. On the one hand, due to the application of XBRL technology, every data and information is marked accordingly. These marks can connect the entire accounting business process, and the information contained in them can be traced back to the original data, so the scope of auditing is extended to the entire information system. For example, if an auditor wants to learn about inventory data while browsing the balance sheet, he can track the inventory ledger, ledger, accounting voucher, or even the original voucher based on the corresponding markup. At the same time, in the XBRL environment, financial data is not only audited, but also includes non-financial data, graphical information, historical information, prediction information, etc. On the other hand, with the application of XBRL, the audit object is not only the data processed by the information system, but also the problems such as whether the XBRL classification standard is accurate, whether the marking is appropriate, and data security, which need to be identified by the auditors.

\subsection{XBRL enables effective continuous audit}

XBRL technology makes continuous auditing a reality. Continuous auditing has been developed as early as the 1990s, but it remains at the theoretical level. The key reason is the lack of corresponding technical support. The emergence of XBRL technology solves this problem and provides a strong condition and foundation for continuous auditing, which enables continuous auditing to develop from the theoretical level to the practical level. Continuous audit refers to an audit technology in which auditors can control and assess risks in a real-time environment and implement real-time monitoring of key business activities. Different from the lag of traditional audit, audit plan, control assessment, risk assessment, audit report and other processes are continuous in the continuous audit process. In the process of continuous audit, if the audit evidence is found to be abnormal during or after the occurrence of business activities, the auditor can make a timely judgment and take corresponding measures to reduce the audit risk. It can be seen that continuous auditing is more advanced than traditional auditing methods, and it can promote the improvement of effectiveness and quality of auditing.

\section{XBRL challenges auditing}

\subsection{Lack of composite audit talent}

At present, there are many auditors, but few generalists and all-rounders, and there are many cases of casting the net widely. There is no key training object, which makes it difficult to adapt to the needs of high-tech content auditing. If you do not understand XBRL's working principle and operation steps, as well as label, classification and other operations, you will not be able to conduct better auditing. In addition, at present, some auditors still follow the traditional auditing concept and do not keep pace with The Times. They are still limited by the existing auditing methods and have little enthusiasm for XBRL auditing.

\subsection{Information security issues in the audit process}

As XBRL plays its role in a web-based platform, the Internet platform may cause the enterprise's financial information to be leaked and tampered. As the financial information of an enterprise is the lifeblood of the enterprise, if relevant financial data is leaked in large quantities, it will put the enterprise at a disadvantage in the market and also cause the disorder of market economic order. In addition, the security of information is the most important issue that an audit must address, as the instability of the system makes it easier for some criminal ACTS of malicious theft of company 
secrets.

\subsection{Increase audit risk}

In the audit process, we not only evaluate and verify the existence of major misstatement of financial data, but also check the XBRL information system. XBRL makes use of computer technology. Since there are certain risks in the computer system itself, the audit content should increase the examination of the computer system in the XBRL environment. Secondly, if enterprises cannot properly use the XBRL classification standard, it will lead to misstatement in the audit process and increase the audit risk. In addition, whether the company's handling of XBRL system is legal and whether the transfer of financial data is safe will also have an impact on the audit risk.

\section{Relevant countermeasures}

\subsection{Pay attention to the cultivation of composite audit personnel}

Although "separate lines are like mountains", nowadays, with the rapid development of economy, the knowledge of a single discipline can no longer meet the demand of market development. As the XBRL requires both financial, auditing, proficient in the relevant professional knowledge, at the same time of computer technology and skilled talents, therefore, the auditor to diversified development, in mastering the relevant audit work at the same time, should also be familiar with other related majors, such as legal, financial, computer and so on, understanding of the specification file of XBRL, familiar, and can identify the enterprise about XBRL tags to define whether appropriate, etc. China should also pay attention to the cultivation of XBRL auditing talents, strengthen the construction of XBRL auditing personnel, timely carry out XBRL related training for auditors, and add XBRL related knowledge in some accounting and auditing exams. Not only truly master XBRL's work essentials from the theoretical system, but also go hand in hand with the development of the enterprise. At the same time pay attention to practice, enhance the capacity of the actual work of auditors, to solve different problems in the usual work pay attention to accumulate work experience, study repeatedly the audit skills, learn to extrapolate, what to learn as much as possible into the practical work, to develop the sensitivity of the audit things, being able to find its essence at a crucial moment in time, in practice to achieve their own quality requirements, and constantly improve the audit work.

\subsection{Build corresponding information security system}

The network system has certain risks. If the backward system and some artificial attacks make the enterprise's financial information leak out a lot, the loss to it is inestimable. Therefore, in the process of using XBRL technology, corresponding technical measures should be taken to ensure the security of information. First, the data is encrypted. It can be encrypted by having different reading rights for different people. Access permissions are also set in each business process; Encrypt the entire XBRL document or some important data in it. Secondly, set up a firewall, installed strong anti-virus software. When the system is open, it is likely to be attacked by various viruses and hackers. Setting up a firewall can effectively prevent possible damage. Finally, after each data update, the data should be backed up and archived in time to avoid the loss of relevant data.

\subsection{Develop applicable auditing software}

Based on the characteristics of XBRL, the development of auditing software with strong applicability is the focus and difficulty of current auditing software development. In the specific development process, the domestic and foreign advanced achievements can be used for reference. For example, at present, western countries use modularized and embedded audit software packages to audit enterprises. Once there are operations in the enterprise financial system that violate relevant regulations, the audit procedures can be made to carry out related work, detect and analyze the 
places in doubt, and achieve the purpose of real-time audit. In addition, one of the important factors that affect the audit result is data analysis and mining ability, therefore needs by building audit analysis platform, reasonable using the method of data mining, fast and deep analysis of huge amounts of data, is not only the calculation of financial data and other indicators, quantitative analysis, but also to the qualitative analysis of all kinds of information, in order to find the data between each other, more in-depth mining problems, so as to timely find audit suspects, evaluation of audit risk, improve the audit effectiveness and efficiency.

Nowadays, with the rapid development of the Internet era, XBRL based on computer network and cross-platform operation has an extraordinary development space in social market economic activities. The research of XBRL technology is the only way to build accounting and auditing informatization in the economic field. The new network financial report based on XBRL fully plays the role of value increment in the audit field provided in the network era. In China's economic field, the construction, research and application of XBRL make positive contributions to the construction of China's accounting informatization, improvement of audit efficiency and quality, and improvement of socialist market economic system.

\section{Acknowledgments}

This work is supported by National Social Science Fund Project 15BJY017; this work is supported by Heilongjiang Provincial Social Science Fund Project "Research on the Construction of Heilongjiang Province Financial Sharing Platform Based on the Perspective of Blockchain Technology" (18JYE672).

\section{References}

[1] Qu xiaolong, Yu guangji and Chen Jun. On the implementation of audit based on XBRL in the network environment [J]. Friends of accounting, 2010, (4):94-95

[2] Zhang Liucheng. Research of Innovation and Entrepreneurship Education in Harbin University of Commerce [J]. Social Science and Humanity, 2015(76), pp. 130-133

[3] Zhang Liucheng. Application and Analysis of Witkey Mode in Network Economy [J]. Advances in Social Science, Education and Humanities Research, 2015(31), pp. 178-181

[4] Zhang Liucheng. The Research and Innovation of Witkey Mode under the New Era [J]. Advances in Education Research, 2015(11), pp. 102-105.

[5] Zhang Liucheng. Research on the problems of the application of XBRL financial statement in small and medium sized enterprises [J]. Advances in Social Science, Education and Humanities Research, 2016(59), pp. 1421-1424

[6] Zhang Liucheng. Application-oriented Institutes Innovation Thinking and Practice of Talent Training Mode [J]. Advances in Social Science, Education and Humanities Research, 2016(59), pp. 1425-1429

[7] Zhang Liucheng. Analysis on the future development of cloud Education [J]. Advances in Social Science, Education and Humanities Research,2016(59), pp. 1477-1480

[8] Zhang Liucheng. Research on the construction of education service platform based on Cloud Computing [J]. Advances in Social Science, Education and Humanities Research, 2016(59), pp. 1481-1484

[9] Zhang Liucheng. Application Prospect of Block Chain Technology in Accounting Industry,2018 International Conference on Mechatronics Engineering and Computer Sciences(ICMECS 2018). IEEE, 2018:559-562.

[10] Zhang Liucheng, Chen Meizhi. The analysis of the deep processing industry of agricultural products and strategy in Heilongjiang Province,2018 International Conference on Mechatronics 
Engineering and Computer Sciences(ICMECS 2018). IEEE, 2018:568-572.

[11] Zhang Liucheng. Impact of Block-Chain Technology on Auditing, 2018 International Conference on Mechatronics Engineering and Computer Sciences (ICMECS 2018). IEEE, 2018: 573-577.

[12] Zhang Liucheng. Data Reliability Research on Accounting Information System Based on Block Chain Technology, 2018 International Conference on Mechatronics Engineering and Computer Sciences (ICMECS 2018). IEEE, 2018:604-607. 